
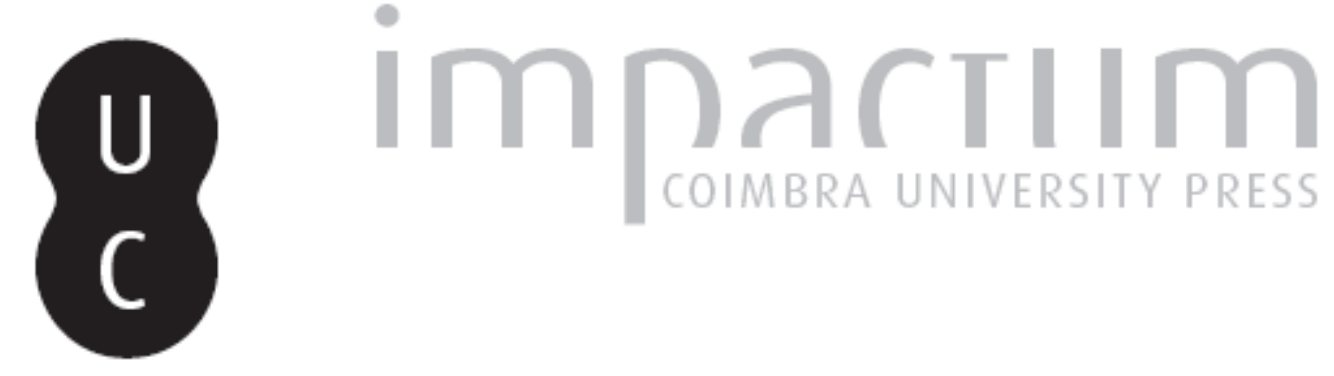

Resenha: Souza Pereira, Rosalie Helena de (2016, org.). Na senda da razão: filosofia e ciência no Medievo judaico

Autor(es): $\quad$ Filho, Juvenal Savian

Publicado por: Imprensa da Universidade de Coimbra

URL persistente:

URI:http://hdl.handle.net/10316.2/43401

DOI:

DOI:https://doi.org/10.14195/1984-249X_22_15

Accessed : $\quad$ 26-Apr-2023 09:25:08

A navegação consulta e descarregamento dos títulos inseridos nas Bibliotecas Digitais UC Digitalis, UC Pombalina e UC Impactum, pressupõem a aceitação plena e sem reservas dos Termos e Condições de Uso destas Bibliotecas Digitais, disponíveis em https://digitalis.uc.pt/pt-pt/termos.

Conforme exposto nos referidos Termos e Condições de Uso, o descarregamento de títulos de acesso restrito requer uma licença válida de autorização devendo o utilizador aceder ao(s) documento(s) a partir de um endereço de IP da instituição detentora da supramencionada licença.

Ao utilizador é apenas permitido o descarregamento para uso pessoal, pelo que o emprego do(s) título(s) descarregado(s) para outro fim, designadamente comercial, carece de autorização do respetivo autor ou editor da obra.

Na medida em que todas as obras da UC Digitalis se encontram protegidas pelo Código do Direito de Autor e Direitos Conexos e demais legislação aplicável, toda a cópia, parcial ou total, deste documento, nos casos em que é legalmente admitida, deverá conter ou fazer-se acompanhar por este aviso.

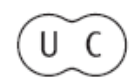




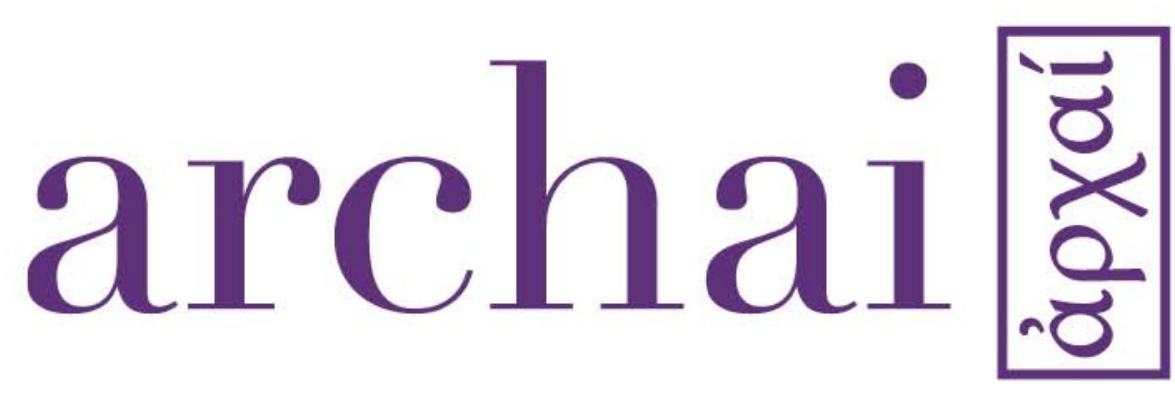

Revista sobre as origens do pensamento ocidental Journal on the Origins of Western Thought

22 | Jan.-Apr. 2018 


\section{Souza Pereira, Rosalie Helena de (2016, ORg.). NA SENDA DA RAZÃO: FILOSOFIA E CIÊNCIA NO MEDIEVO JUDAICO. São Paulo, Perspectiva}

SAVIAN FILHO, J. (2018). Resenha: Souza Pereira, Rosalie Helena de (2016, org.). Na senda da razão: filosofia e ciência no Medievo judaico. São Paulo, Perspectiva. Archai, n. ${ }^{\circ}$ 22, Jan.-Abr., p. 375-380 DOI: https://doi.org/10.14195/1984-249X_22_15

Um acontecimento! Um acontecimento notável!

Dizer isso foi a melhor maneira encontrada para iniciar a resenha do livro organizado por Rosalie Helena de Souza Pereira, ainda que não seja uma forma propriamente adequada para um texto acadêmico.

A exceção se justifica, no entanto, pelo fato de que o significado dessa publicação transcende em muito a 


\section{archai圈}

no 22, Jan.-Apr. 2018

Juvenal Savian Filho, 'Souza Pereira, Rosalie Helena de (2016, org.). $\mathrm{Na}$ senda da razão: filosofia e ciência no Medievo judaico. São Paulo, Perspectiva, p. 375-380 sua importância para o mundo universitário e inscreve-se, sem sombra de dúvida, no campo de tudo o que contribui não apenas para o enriquecimento cultural, mas também e, sobretudo, humanizador. Aliás, humanizador é um termo cujo significado também transcende o de outro que lhe é próximo, o termo humanista, pois não se trata aqui de simplesmente evocar o reconhecimento que merecem os outros seres humanos, o ser humano em geral e os indivíduos, mas, acima de tudo, a atividade de tornar-se humano. Essa atividade pressupõe a convivência com o outro; e tanto mais será intensa e capaz de desenvolver o que de mais humano há em nós quanto mais envolver a relação com o estrangeiro; afinal, como diz Julia Kristeva em Estrangeiros para nós mesmos, viver com o estrangeiro põe-nos em contato com a possibilidade de "ser outro", possibilidade esta que se entende não apenas no sentido humanista da nossa aptidão para aceitar o outro, mas de estar ou colocar-se no lugar do outro, o que equivale a pensar sobre si mesmo e a fazer-se "outro ou estrangeiro para si mesmo". Numa palavra, trata-se de ver a si mesmo na condição de estrangeiro ou na condição de "o outro daquele que vê". Tarefa exigente, árdua e certamente interminável, mas absolutamente necessária em meio às obscuridades que se instalaram nos dias atuais, marcados pela rejeição do diferente e do contraditório por todos os cantos do planeta. Um pouco do iluminismo filosófico medieval faria bem à vida contemporânea.

Seguir, então, Na senda da razão: filosofia e ciência no Medievo judaico é colocar-se em um caminho no qual vários estrangeiros se apresentam e auxiliam o leitor pretensamente "não oriental" ou "não judeu" a entender um pouco melhor, pela identificação de

\section{6


semelhanças e pelo contraste de diferenças, quem ele mesmo é. É por isso que o livro objeto desta resenha é um acontecimento memorável, pois seu interesse não se restringe ao trabalho de pesquisa especializada sobre formas medievais judaicas de pensamento filosófico e científico, mas se amplia para o trabalho de humanização. Assim, mais do que apenas contribuir com o trabalho especializado, este livro enriquece sobremaneira a cultura lusófona por registrar, em Língua Portuguesa literária e filosófica, estudos rigorosos sobre pensadores judeus medievais (sem deixar, obviamente, de também interessar aos especialistas, uma vez que vários artigos são inéditos). Se se tem em vista a quase total inexistência no Brasil de obras sobre a filosofia judaica medieval, compreende-se definitivamente a importância do livro organizado por Rosalie Helena de Souza Pereira, ela que, em 2007, publicou dois livros homólogos e dedicados à filosofia medieval islâmica (Busca do conhecimento: ensaios de filosofia medieval no Islã, São Paulo: Paulus; O Islã Clássico: itinerários de uma cultura, São Paulo: Perspectiva).

$\mathrm{O}$ arco de tempo coberto por $\mathrm{Na}$ senda da razão compreende os seis séculos da Idade Média em que tradicionalmente se identifica alguma forma de pensamento medieval judaico. Parte-se, portanto, de Sa'adia Gaon, que viveu na passagem do séc. IX ao séc. $\mathrm{x}, \mathrm{e}$ chega-se a Hasdai Crescas, que viveu na passagem do séc. XIV ao séc. XV. Os textos são estudos de grandes especialistas de universidades estrangeiras, com exceção do Prof. Nachman Falbel e do Prof. Alexandre Leone, ambos da Universidade de São Paulo. Seria inapropriado pretender apresentar resumidamente todos os capítulos do livro em uma resenha, mas também seria uma falta grave não dar ao leitor uma ideia do conteúdo da

\section{archai蒡}

no 22, jan.-apr. 2018

Juvenal Savian Filho, 'Souza Pereira, Rosalie Helena de (2016, org.). Na senda da razão: filosofia e ciência no $\mathrm{Me}$ dievo judaico. São Paulo, Perspectiva, p. $375-380$ 


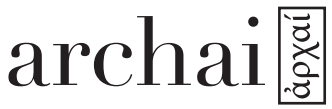

no 22, Jan.-Apr. 2018

Juvenal Savian Filho, 'Souza Pereira, Rosalie Helena de (2016, org.). $\mathrm{Na}$ senda da razão: filosofia e ciência no Medievo judaico. São Paulo, Perspectiva, p. 375-380 obra. Por isso, aqui seguem os títulos dos capítulos e os nomes dos autores na ordem em que aparecem no livro: (1) A obra exegética e filosófica de Sa'adia Gaon: a realização de um líder, de Haggai Ben-Shammai; (2) Criação e emanação em Isaac Israeli: uma reconsideração, de Alexander Altmann; (3) Filosofia e poética no pensamento de Salomão Ibn Gabirol, de Nachman Falbel; (4) A matéria última como manifestação oculta de Deus: Ibn Gabirol e a expressão pseudoempedocleana al-unșur al-awwal (o elemento fundamental), de Sarah Pessin; (5) Ibn Paquda, figura-chave do pensamento judaico e universal, de Joaquín Lomba; (6) A interpretação de Abraão Bar Hiyya do relato da criação do homem e do relato do jardim do Éden, de Sara Klein-Braslavy; (7) O corpus científico de Abraão ibn Ezra, de Shlomo Sela; (8) Yehudá Halevi e a filosofia, de Rafael Ramón Guerrero; (9) Abraão Ibn Daud e sua obra A fé sublime, de Amira Eran; (10) Maimônides e o Deus dos filósofos, de Samuel Scolnicov; (11) Tensões e encontros no pensamento de Maimônides entre o aristotelismo medieval e a tradição rabínica, de Alexandre Leone; (12) A ética na obra de Maimônides, de Nachman Falbel; (13) A declaração de Maimônides sobre a ciência política, de Leo Strauss; (14) Comentário de Maimônides à Bíblia, de Sara Klein-Braslavy; (15) A psicologia de Maimônides e de Yehudá Halevi, de Lenn E. Goodman; (16) A legislação da verdade: Maimônides, os almôadas e o iluminismo judaico do século XIII, de Carlos Fraenkel; (17) A alquimia na cultura judaica medieval: uma ausência notada, de Gad Freudenthal; (18) A ciência na cultura medieval judaica do sul da França, de Gad Freudenthal; (19) De Maimônides a Samuel ibn Tibbon: interpretando o judaísmo como religião filosófica, de Carlos Fraenkel; (20) O Al-Farabi de Falaqera: um exemplo da judaização dos falāsifa 
muçulmanos, de Steven Harvey; (21) A transmissão da filosofia e da ciência árabe: reconstrução da "Biblioteca Árabe" de Shem Tov ibn Falaqera, de Mauro Zonta; (22) Uma solução averroísta para uma perplexidade maimonídea, de Seymour Feldman; (23) Um selo dentro de um selo: a marca do sufismo nos ensinamentos de Abraão Abuláfia, de Harvey J. Hames; (24) Narboni (1300-1362) e a simbiose filosófica judeo-árabe, de Maurice-Ruben Hayoun; (25) Salvar sua alma ou salvar os fenômenos: soteriologia, epistemologia e astronomia em Gersônides, de Gad Freudenthal; (26) Tensões nas e entre as teorias de Maimônides e Gersônides sobre a profecia, de Idit Dobbs-Weinstein; (27) Elementos cabalísticos no livro Luz do nome ('Or há-Shem) de Rabi Hasdai Crescas, de Zev Harvey.

Pensando da perspectiva de interesses propriamente acadêmicos e especializados, vários aspectos desse conjunto de textos poderiam ser destacados aqui. Dois merecem atenção: em primeiro lugar, cabe ressaltar não apenas a frequentação mútua de pensadores judeus, cristãos e muçulmanos no $\mathrm{Me}$ dievo, mas sobretudo a influência recíproca que autores dessas três orientações exerceram entre si; e o livro organizado por Rosalie Helena de Souza Pereira permite ver tal influência. Além disso, o livro tem outro mérito, o de participar de maneira esclarecedora no debate instalado entre medievalistas, há alguns anos, a respeito de uma possível identidade do pensamento "medieval": dada a implosão da imagem de uma Idade Média homogênea e filosoficamente cristã, haveria alguma forma de unir as formas filosóficas cultivadas no período a que tradicionalmente se costuma chamar de Medievo? A característica que tem sido identificada e defendida por importantes

\section{archai蒡}

no 22, jan.-apr. 2018

Juvenal Savian Filho, 'Souza Pereira, Rosalie Helena de (2016, org.). $\mathrm{Na}$ senda da razão: $f i$ losofia e ciência no $\mathrm{Me}$ dievo judaico. São Paulo, Perspectiva, p. $375-380$ 


\section{archai圈}

no 22, Jan.-Apr. 2018

Juvenal Savian Filho, 'Souza Pereira, Rosalie Helena de (2016, org.). $\mathrm{Na}$ senda da razão: filosofia e ciência no Medievo judaico. São Paulo, Perspectiva, p. 375-380 medievalistas como critério para unir as formas filosóficas medievais é o fato de os diferentes pensadores, sem exceção (até onde se sabe), considerarem a revelação bíblica como fonte de conhecimento e de investigação filosófica. Não se trata de retomar o clichê superado da "filosofia serva da teologia", mas de perceber que os filósofos, no Medievo, partilhavam principalmente a tradição bíblica da fé na criação e dela extraíam consequências filosóficas em termos propriamente filosóficos. Desse ponto de vista, porém, a "Idade Média" ou o "Medievo" poderia ser estendida, no mínimo, até Fílon de Alexandria, por um lado, e talvez, por outro lado, como tem defendido o medievalista italiano Giulio d'Onofrio, até os séculos XV-XVI, com os Concílios de Constança (1492), Basileia (1431-1449) e Trento (1545), cujos cânones assumem abertamente as fraturas político-religiosas e a cisão entre a busca filosófica moderna e o horizonte bíblico do pensamento. Obviamente continuará vigoroso nos séculos seguintes, em maior ou menor grau, o modelo de pensamento que considera o horizonte da revelação bíblica. Mais ainda, continuará vigorosa a inspiração que se nutre das três orientações monoteístas (haja vista autores como Edith Stein, Martin Buber, Emmanuel Lévinas, Simone Weil, Michel Henry, para não falar de Walter Benjamin, Max Horkheimer, Heschel, entre tantos outros). Entender as raízes e as motivações profundas dessa inspiração é algo com que contribui inequivocamente o livro organizado por Rosalie Helena de Souza Pereira.

Submetido em Novembro e aceite para publicação em Dezembro, 2016

\section{0}

